\title{
A Simple Method for Assessing Severity of Common Root Rot on Barley
}

\author{
Mohammad Imad Eddin Arabi* and Mohammad Jawhar \\ Department of Molecular Biology and Biotechnology, Atomic Energy Commission of Syria, P.O. Box 6091, Damascus, Syria \\ (Received on September 4, 2013; Revised on September 22, 2013; Accepted on September 22, 2013)
}

\begin{abstract}
Common root rot caused by Cochliobolus sativus is a serious disease of barley. A simple and reliable method for assessing this disease would enhance our capacity in identifying resistance sources and developing resistant barley cultivars. In searching for such a method, a conidial suspension of $C$. sativus was dropped onto sterilized elongated subcrown internodes and incubated in sandwich filter paper using polyethylene transparent envelopes. Initial disease symptoms were easily detected after 48h of inoculation. Highly significant correlation coefficients were found in each experiment (A, B and C) between sandwich filter paper and seedling assays, indicating that this testing procedure was reliable. The method presented facilitates a rapid pre-selection under uniform conditions which is of importance from a breeder's point of view.
\end{abstract}

Keywords : barley, Cochliobolus sativus, common root rot, resistance test

Cochliobolus sativus (Ito \& Kuribayashi) Drechs. ex Dastur (anamorph: Bipolaris sorokiniana (Sacc.) Shoemaker), the causal agent of common root rot (CRR), is an important pathogen of barley (Hordeum vulgare L.) found worldwide (Mathre et al., 2003). This pathogen is considered economically important because it can cause a marked reduction in yield and quality of the crop (Fernandez et al., 2009). CRR pathogen produces a brown to black discoloration of the subcrown internode (SCI) (Kumar et al., 2002; Verma et al., 1976).

Reaction of barley to CRR pathogen is commonly evaluated under field conditions at the seedling and adult plant stages by determining the visible disease symptoms as a percentage of SCIs (Kokko et al., 1995). This method is time-consuming and several environmental interactions make it impossible to obtain error-free estimates (Duczek et al., 1985; Meldrum et al., 2004). In a previous work (Arabi and Jawhar, 1999) gibberellins technique for SCI elongation has been used for evaluating barley resistance to CRR

\footnotetext{
*Corresponding author.

Phone) 963-11-2132580, FAX) 963-11-6112289

E-mail) ascientific@aec.org.sy
}

pathogen. However, this method is costly since it needs hormone, antibiotics and Petri dishes.

A fast, accurate, and precise screening method that can be used to identify sources of tolerant, partially resistant, and pathotype specific resistant barley germplasm would aid in the development of cultivars for optimal control of $C$. sativus. The purpose of this study was to develop a reliable laboratory method for measuring the degree of CRR severity using sandwich filter paper in a simple and rapid way to solve assessment associated with the susceptibility of barley to $C$. sativus in the field.

Host genotypes. Five barley cultivars used in this study were chosen for their wide genetic variability for $C$. sativus reaction from highly susceptible to highly resistant (Arabi and Jawhar, 1999) (Table 1). The universal susceptible cultivar WI 2291 from Australia was included in each set as a check.

Preparation of inocula and inoculation. Isolates of $C$. sativus were obtained from barley SCIs showing CRR symptoms in different regions of northern Syria. During a preliminary study, five isolates (single spore) were selected on the basis of morphological and physiological criteria. The fungus was grown separately in $9 \mathrm{~cm}$ Petri dishes containing potato dextrose agar (PDA, DIFCO, Detroit, MI. USA) with $13 \mathrm{mg} / \mathrm{l}$ kanamycin sulphate added after autoclaving and incubated at $22 \pm 1{ }^{\circ} \mathrm{C}$ in the dark for 10 days to allow mycelial growth and sporulation. A mixture of equal ratio of each isolate was used in this study. The conidial suspension was adjusted to $5 \times 10^{5}$ condia/ml and $40 \mathrm{ml}$ of spore suspension was mixed in a plastic Petri dish with $50 \mathrm{~g}$ sterile neutralized peat. Part of seeds of the five genotypes were surface-sterilized with $5 \%$ sodium hypochlorite solution for $5 \mathrm{~min}$ and then soaked three times in sterile distilled water. They were inoculated by mixing thoroughly with conidial inoculum. After inoculation, seeds were grown in pots.

Pot experiment. Inoculated seeds were sown into 21 pots filled with sterilized peatmoss, and arranged in a randomized complete block design with three replicates. The 
deep seeding was $6 \mathrm{~cm}$ (Kokko et al., 1995). Each experimental unit consisted of five pots of ten seeds per genotype. Pots were placed in a growth chamber at temperatures $22 \pm 1{ }^{\circ} \mathrm{C}$ (day) and $17 \pm 1{ }^{\circ} \mathrm{C}$ (night) with a daylength of 12 $\mathrm{h}$ and a relative humidity of $80-90 \%$. Seedlings were irrigated with Knop's nutrient solution $\left(1 \mathrm{~g} \mathrm{NaNO}_{3} ; 0.25 \mathrm{~g}\right.$ $\mathrm{KNO}_{3} ; 0.25 \mathrm{~g} \mathrm{MgSO}_{4} \cdot 7 \mathrm{H}_{2} \mathrm{O} ; 0.25 \mathrm{~g} \mathrm{KH}_{2} \mathrm{PO}_{4}$; and $10 \mathrm{mg}$ $\mathrm{FeCl}_{3}$ per $1000 \mathrm{ml}$ water). To elongate the SCIs, the second part of seeds of the five genotypes was sown for one week in the same manner but without inoculation with $C$. sativus.

Sandwich filter paper experiment. After one week of planting, the non-inoculated SCIs were taken and washed three times using sterile distilled water. Ten SCIs per genotype were inoculated with a mixture of five isolates of C. sativus ( $5 \mathrm{ml}$ of the conidial suspension) and incubated under similar conditions as mentioned above for 5 days in sandwich filter paper placed into polyethylene transparent envelopes SCIs controls were treated with sterile distilled water. The experiment was repeated three times.

Disease assessment. The infection response based on the measurement of individual SCI discoloration (\%) was assessed 7 weeks for seedling assay, and five days for sandwich filter paper method post inoculation. The 0-5 scale as described by Kokko et al. (1995) was used for the two both methods.

Statistical analysis. Data of different tests were analyzed to determine whether there was a significant test $\times$ genotype interaction. The relationship among disease ratings on sandwich filter paper assay and seedlings was examined by studying the correlation among genotypes means in all different experiments using STAT-ITCF program (Anonymous, 1988).

The disease symptoms (discoloration and necrosis of the SCIs) were easily detected on the SCIs placed into the transparent envelope after $48 \mathrm{~h}$ of inoculation (Fig. 1). SCI discoloration was typically observed in infected plants with the severity values being consistently higher in the suscep-
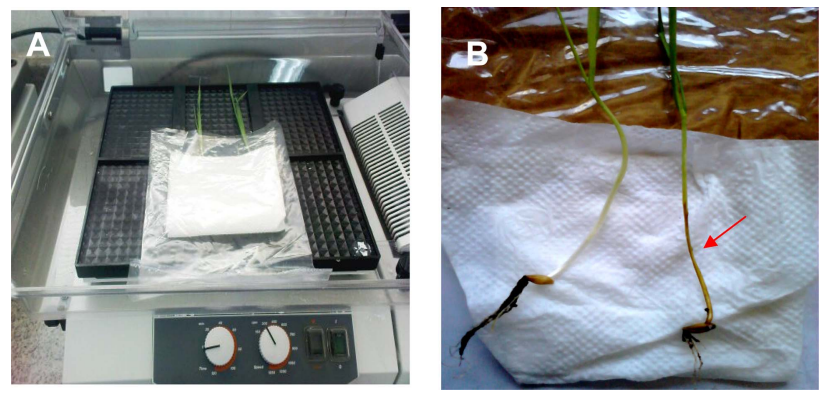

Fig. 1. A Photographs of a sandwich filter paper method; (A) Incubation of barley seedlings (cv. WI 2291) after C. sativus inoculation. (B) Infected seedling with brown lesions (arrow) after 5 days of inoculation (right side), and the clean control (left side).

Table 1. Developmental stages of CRR on barley using sandwich filter paper method

\begin{tabular}{lc}
\hline \hline Disease development & $\begin{array}{c}\text { Hours after } \\
\text { inoculation }\end{array}$ \\
\hline SCI white color & 24 \\
Unblemished creamy white color & 48 \\
Stunted chlorotic lesions & 72 \\
Elongated dark brown lesions & 96 \\
A darkening or reddish brown decay & 120 \\
\hline
\end{tabular}

tible genotypes in both experiments (Tables 1 and 2).

Analysis of variance showed that there were significant differences among genotypes. Infection responses of barley genotypes to all $C$. sativus were summarized in Table 2. Highly significant correlation coefficients were found in each experiment (A, B and $\mathrm{C}$ ) between sandwich filter paper and seedling assays (Fig. 2), indicating that this testing procedure was reliable.

Inoculation with the $C$. sativus virulent pathotypes increased discoloration of the SCIs on susceptible genotypes in transparent envelopes and pot experiments. Both methods showed that Thibaut was resistant, whereas the ratings of genotypes shown to be either moderately resistant or susceptible to CRR pathogen were quite consistent among

Table 2. Disease rating of barley reaction to CRR $\left(5 \times 10^{5}\right.$ conidia/ml $)$ by using standard seedling inoculation test (I) and the sandwich filter paper method (II)

\begin{tabular}{|c|c|c|c|c|c|c|c|}
\hline \multirow{2}{*}{ Genotype } & \multirow{2}{*}{ Source } & \multicolumn{3}{|c|}{ (I) } & \multicolumn{3}{|c|}{ (II) } \\
\hline & & A & B & $\mathrm{C}$ & A & B & $\mathrm{C}$ \\
\hline Arrivate & USA & $91.67 \mathrm{a}$ & $94.33 \mathrm{a}$ & $89.00 \mathrm{a}$ & $94.00 \mathrm{a}$ & $97.02 \mathrm{a}$ & $88.11 \mathrm{a}$ \\
\hline WI2291 & Australia & $81.67 \mathrm{a}$ & $90.00 \mathrm{~b}$ & $80.33 a$ & $91.00 \mathrm{a}$ & $88.11 \mathrm{a}$ & $85.07 \mathrm{a}$ \\
\hline Golf & England & $55.67 \mathrm{~b}$ & $65.33 b$ & $53.67 \mathrm{~b}$ & $63.69 \mathrm{~b}$ & $57.70 \mathrm{~b}$ & $52.13 b$ \\
\hline Igri & Germany & $47.63 c$ & $44.13 c$ & $33.17 \mathrm{c}$ & 41.01c & $37.10 \mathrm{c}$ & $32.23 b$ \\
\hline Thibaut & France & $17.00 \mathrm{~d}$ & $16.00 \mathrm{~d}$ & $16.67 d$ & $21.00 \mathrm{~d}$ & $19.45 \mathrm{~d}$ & $16.33 c$ \\
\hline
\end{tabular}

Values within a column followed by different letters differ significantly at $P=0.001$ (Newman-Keuls). 

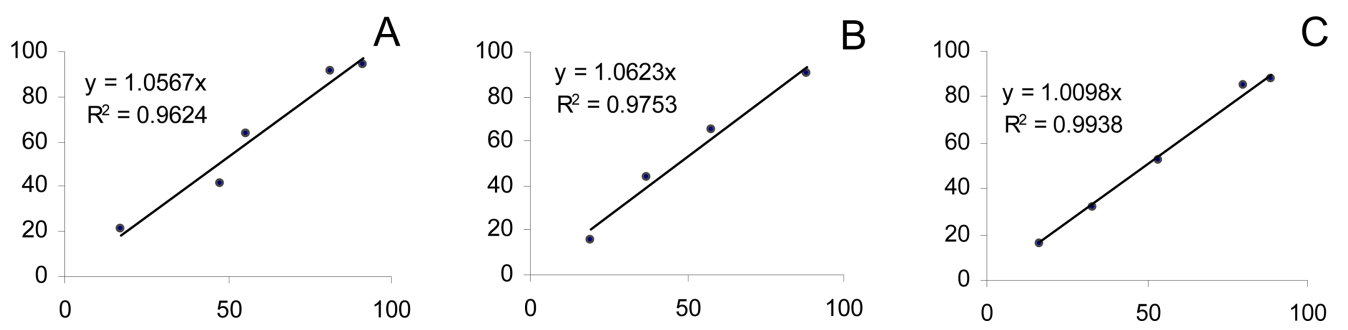

Fig. 2. A correlation between sandwich technique and seedling assay in three experiments (A, $B$ and $C)$.

different tests (Table 2). The results clearly indicated that the reaction of barley genotypes to $C$. sativus was similar in the two methods and that the transparent envelop was useful for CRR evaluation in a short time.

Different factors have been shown to influence the susceptibility of barley to CRR pathogen under field conditions (Van Leur et al., 1997). These researchers demonstrated that susceptibility was related to both inoculum level and climate conditions. In our sandwich filter paper experiments, the level of inoculum was controlled. Therefore, precise assessment could be made on the barley reaction to CRR disease. Furthermore, the soil may contain other fungi and bacteria that can cause SCI rotting, which can lead to misdiagnosis of infection symptoms with C.sativus. In addition, high soil moisture may also lead to SCI discoloration similar to that caused by a $C$. sativus infection.

C. sativus is pathogenic to many gramineous hosts; many researchers are therefore studying the diseases caused by this fungus (Fernandez and Conner, 2011; Tinline, 1988). In particular, abundant research on its pathogenicity and on plant-pathogen interactions at the macro and molecular levels has been conducted in barley. Since the fungus can infect barley at any growth stage and causes serious yield loss (Mathre et al., 2003), the risk of escape of highly pathogenic test isolates from glasshouses into barley production areas needs to be minimized.

The sandwich filter paper method is both simple and rapid; it enables the resistance of all plants to be evaluated rapidly under uniform conditions after 5 days of inoculation compared with 7 weeks in pots in the common method. Moreover, this method can help to replicate infection assays, and to test large numbers of isolates and barley genotypes in a short and early time in breeding programs.

\section{Acknowledgments}

The authors thank the Director General of AECS and the Head of the Molecular Biology and Biotechnology Department for their continuous support throughout this work. Thanks also extended to Dr. B. Al-safadi for critical reading of the manuscript.

\section{References}

Anonymous, 1988. STAT-ITCF, Programme, MICROSTA, realized by ECOSOFT, $2^{\text {nd }}$ Ver. Institut Technique des Cereals et des Fourrages Paris, pp. 55.

Arabi, M. I. E. and Jawhar, M. 1999. A rapid technique for determining common root rot reaction in barley. Plant Breed. 118:278-280.

Duczek, L. J., Verma, P. R. and Spurr, D. T. 1985. Effect of inoculum density of Cochliobulus sativus on common root rot of wheat and Barley. Can. J. Plant Pathol. 7:382-386.

Fernandez, M. R. and Conner, R. L. 2011. Root and crown rot of wheat. Prairie Soils Crops J. 4:151-157.

Fernandez, M. R., Holzgang, G. and Turkington, T. K. 2009. Common root rot and crown rot of barley crops across Saskatchewan and in north-central Alberta. Can. J. Plant Pathol. 31:96-102.

Kokko, E. G., Conner, R. L., Kozub, G. C. and Lee, B. 1995. Effects of common root rot on discoloration and growth of spring wheat root system. Phytopathology 85:203-208.

Kumar, J., Schafer, P., Huckelhoven, R., Langen, G., Baltruschat, H., Stein, E., Nagarajan, S. and Kogel, H. K. 2002. Bipolaris sorokiniana, a cereal pathogen of global concern: cytological and molecular approaches towards better control. Mol. Plant Pathol. 3:185-195.

Van Leur, J. G., Alamdar, M. Z. and Khawatmi, S. 1997. Effect of Cochliobolus sativus on yields of barley under experimental conditions in northern Syria. Aust. J. Agric. Res. 48:1-7.

Mathre, D. E., Johnston, R. H. and Grey, W. E. 2003. Diagnosis of common root rot of wheat and barley. Online. Plant Health Progress doi:10.1094/PHP-2003-0819-01-DG.

Meldrum, S. I., Platz, G. J. and Ogle, H. J. 2004. Pathotypes of Cochliobolus sativus on barley in Australia. Aust. Plant Pathol. 33:109-114.

Tinline, R. D. 1988. Cochlliobolus sativus, a pathogen of wide host range. Pages. 113-122. in: Advances in Plant Pathology. Vol. 6 D.S. Ingram and P.H. Williams, eds. Academic Press, London.

Verma, P. R., Morrail, R. A. A. and Tinline, R. D. 1976. The effect of common root rot on components of grain yield in Manitou wheat. Can. J. Bot. 54:2888-2892. 